\title{
Padrões fenológicos de 111 espécies de Cerrado em condições de cultivo
}

\author{
Natashi A. Lima Pilon ${ }^{1,2,4}$, Renata Giassi Udulutsch ${ }^{1}$ e Giselda Durigan ${ }^{3}$
}

Recebido: 9.01.2015; aceito: 23.03.2015

\begin{abstract}
Phenological patterns of 111 Cerrado species under cultivation). The knowledge on the phenological patterns for a broad group of species is an important tool to elucidate the function and structure of plant communities. Aiming to describe the phenological rhythms of Cerrado species being cultivated and to verify if they follow the patterns observed in the native communities, we recorded, every two weeks along four years, the phenology of reproductive (flowering, and fruiting) and vegetative (leaf shedding and sprouting) processes of 111 species of Cerrado in the Arboretum of Floresta Estadual de Assis, São Paulo State, Brazil. We elaborated a phenogram containing the occurrence of each phenophase in each month, for each species, as well as the frequency of these phenophases during the years of observations. We identified general patterns of fruiting, flowering and leaf dynamics for the whole set of species planted, which correspond to those found in the literature for the phenology of natural communities of Cerrado.
\end{abstract}

Keywords: flowering, fructification, leaf dynamics, phenology, restoration

RESUMO - (Padrões fenológicos de 111 espécies de Cerrado em condições de cultivo). O conhecimento dos padrões fenológicos para um amplo grupo de espécies é importante ferramenta para elucidar o funcionamento e a estruturação de comunidades vegetais. Visando descrever os ritmos fenológicos de espécies de Cerrado e verificar se, em condições de cultivo, o conjunto de espécies segue o padrão observado para a vegetação natural, registramos quinzenalmente, durante quatro anos, a fenologia dos processos reprodutivos (floração e frutificação) e vegetativos (caducifolia e brotação) de 111 espécies de Cerrado cultivadas em arboreto na Floresta Estadual de Assis, SP, Brasil. Elaboramos um fenograma contendo a ocorrência de cada fenofase, mensalmente, para cada uma das espécies, bem como a frequência destas fenofases durante os anos de observações. Identificamos padrões gerais de sazonalidade da frutificação, floração e dinâmica foliar para o conjunto das espécies em condições de cultivo que correspondem ao encontrado na literatura para a fenologia de comunidades naturais de Cerrado.

Palavras-chave: dinâmica foliar, fenologia, floração, frutificação, restauração

\section{Introdução}

A fenologia representa importante aspecto funcional das comunidades vegetais, uma vez que seu ritmo permite predições a respeito de padrões de produtividade primária, disponibilidade de alimento para a fauna ao longo do ano (Oliveira 2008) e também contribui para a compreensão da composição e da distribuição das espécies em comunidades vegetais (Chuine \& Beaubien 2001) e do grau de deciduidade da vegetação. Existe ampla literatura caracterizando os ritmos fenológicos de vegetações savânicas (Monasterio \& Sarmiento 1976, Batalha et al. 1997,
Batalha \& Mantovani 2000, Lenza \& Klink 2006, Munhoz \& Felfili 2007, Pirani et al. 2009, Silva et al. 2011). No entanto, poucos estudos disponibilizam informações individuais para as espécies, baseadas em vários anos de observações, que englobem possíveis variações entre anos. Também não há estudos que demonstrem que esses padrões podem ser restabelecidos em comunidades em processo de restauração, onde as espécies são cultivadas.

O Cerrado, que representa o bioma Savana no Brasil, compreende amplo gradiente de fisionomias, variando de campos limpos até tipos florestais, como o Cerradão, além de vegetações associadas a cursos

1. Universidade Estadual Paulista "Júlio de Mesquita Filho", Departamento de Ciências Biológicas, Av. Dom Antônio 2100, 19806-900 Assis, SP, Brasil

2. Universidade Estadual de Campinas, Instituto de Biologia, Caixa Postal 6109, 13083 - 865 Campinas, SP, Brazil

3. Instituto Florestal, Floresta Estadual de Assis, Caixa Postal 104, 19802-970 Assis, SP, Brasil

4. Autor para correspondência: natashipilon@gmail.com 
d'água, como a Floresta de Galeria e Matas Ciliares (Eiten 1972). Estudos têm demonstrado que diferentes fatores ambientais, como a duração da estação seca e as propriedades do solo, entre outros, associados aos distúrbios como o fogo, são as grandes forças moduladoras das fisionomias do Cerrado em larga escala (Hoffman et al. 2009, Mews et al. 2011, Veldman et al. 2013). Ecossistemas com marcada sazonalidade climática, como o Cerrado, podem apresentar, como consequência, ampla diversidade de estratégias fenológicas, variando entre as diferentes fitofisionomias, entre os diferentes hábitos (e.g. herbáceo, arbustivo e arbóreo) e mesmo entre os diferentes modos de dispersão (e.g. zoocóricas, anemocóricas e autocóricas) (Monasterio \& Sarmiento 1976, Batalha et al. 1997, Lenza \& Klink 2006, Tannus et al. 2006, Silva et al. 2011). De maneira geral, espécies anemocóricas e autocóricas dispersam suas sementes durante ou no final da estação seca, quando o vento é mais frequente e de maior velocidade, e é baixa a umidade do ar, facilitando a abertura e dispersão dos frutos (Monasterio \& Sarmiento 1976, Batalha \& Mantovani 2000). Nesse período do ano, a biomassa do estrato herbáceo é baixa, permitindo que as sementes alcancem o solo com maior facilidade e germinem logo após as primeiras chuvas. Já as espécies zoocóricas apresentam seus picos de frutos maduros durante a estação chuvosa, quando a elevada umidade do ar proporciona a permanência desses frutos atrativos para a fauna por mais tempo, podendo garantir a dispersão por longas distâncias. Os picos de floração e de brotação ocorrem, principalmente, na transição entre o final da estação seca e início da estação chuvosa, logo após a queda das folhas decorrente do estresse hídrico (Batalha et al. 1997, Batalha \& Martins 2004, Franco et al. 2005, Oliveira 2008).

A compreensão das estratégias fenológicas das espécies de comunidades savânicas é embasada por rica literatura. No entanto, não são encontrados estudos que demonstrem que essas estratégias são mantidas em áreas em processo de restauração. Tal informação representa importante aplicação para que se avalie o funcionamento das comunidades que estão sendo restauradas, ou seja, o quanto elas se aproximam do seu ecossistema de referência neste aspecto. Alguns estudos em outros tipos vegetacionais, como as pradarias, têm demonstrado a importância dos aspectos fenológicos na identificação de melhores períodos para o manejo de fogo, para o fluxo gênico entre indivíduos cultivados e outros da mesma espécie em áreas naturais remanescentes, ou mesmo para determinar similaridade de aspectos estruturais e atributos funcionais entre áreas restauradas e fragmentos naturais (Howe 1994, Selbo \& Snow 2005, Kucharik et al. 2006).

Neste estudo, analisamos os padrões fenológicos reprodutivos e vegetativos para o conjunto total das espécies cultivadas, em comparação com os padrões apresentados na literatura para a sazonalidade dos processos fenológicos em vegetação nativa do Cerrado. Apresentamos ainda, para cada espécie, o período correspondente a cada fenofase, visando facilitar outros estudos que dependem desta informação ou mesmo para dar suporte à colheita de frutos e sementes dessas espécies.

\section{Material e métodos}

Área de estudo - Conduzimos a pesquisa no Arboreto do Cerrado da Floresta Estadual de Assis, SP, localizado pelas coordenadas $22^{\circ} 33^{\prime} 10^{\prime \prime} \mathrm{S}$ e $50^{\circ} 24^{\prime} 05^{\prime \prime} \mathrm{W}$, em altitude de $562 \mathrm{~m}$. O clima da região caracteriza-se por chuvas concentradas nos meses de verão e menores precipitações nos meses de inverno. A temperatura média anual é de $21,8^{\circ} \mathrm{C}$, com a média das máximas de $32,4^{\circ} \mathrm{C}$ e a média das mínimas $8,4^{\circ} \mathrm{C}$ (figura 1). Os solos da unidade são ácidos, com baixa fertilidade e elevados teores de alumínio, e na área do arboreto são do tipo Latossolo Vermelho Distrófico (Max et al. 2007).

Iniciamos a instalação do Arboreto no ano de 2005, por meio do plantio de mudas de espécies características da vegetação do cerrado lato sensu. Sempre que possível, plantamos cinco indivíduos de cada espécie, em quincôncio, com distância variável de acordo com o porte esperado para a espécie. Optamos pela distribuição espacial irregular das espécies para que a paisagem final se assemelhasse a áreas naturais do Cerrado.

Coleta e análise dos dados - Entre as espécies plantadas no Arboreto, selecionamos 111 cujo estágio de desenvolvimento possibilitasse as observações fenológicas pelo menos para caducifolia. O número de indivíduos monitorados por espécie variou entre um e cinco, já que nem todos os indivíduos plantados sobreviveram. Desse modo, monitoramos, no total, 408 indivíduos. Registramos os processos fenológicos quinzenalmente, durante o período de fevereiro de 2009 a março de 2013. Para cada espécie registramos a presença ou ausência de brotação ou formação de folhas novas, queda de folhas evidenciando deciduidade, presença de botões florais ou flores, frutos maduros ou verdes. 
Classificamos a síndrome de dispersão segundo Van der Pijl (1982), segundo o qual as espécies são categorizadas em três grupos: i) zoocóricas - dispersão pela fauna; ii) anemocóricas - dispersão pelo vento, e iii) autocóricas - sem agente dispersor, caracterizada pela auto dispersão.

Para representação das fenofases em cada espécie, elaboramos um fenograma (tabela 1), onde reunimos os dados dos quatro anos de registros.

Utilizamos estatística circular para descrever os padrões fenológicos das espécies segundo Morellato et al. (2010). Para representar a sazonalidade das fenofases, elaboramos histogramas circulares, a partir da frequência média (expressa em porcentagem de espécies apresentando a fenofase em cada mês) entre os quatro anos de observações (figura 2). Calculamos

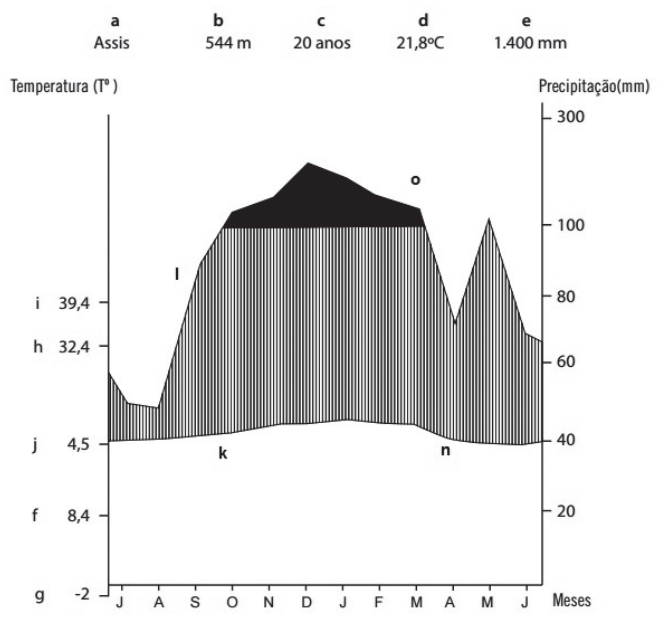

Figura 1. Diagrama climático da Estação Ecológica e Floresta Estadual de Assis, segundo Walter \& Lieth (1967). Local (a); altitude (b); período de observações (c); temperatura média anual (d); precipitação média anual (e); média da temperatura mínima do mês mais frio (f); menor temperatura observada (g); média da temperatura máxima do mês mais quente $(\mathrm{h})$; maior temperatura observada (i); variação média diária da temperatura (j); curva da temperatura média mensal $(\mathrm{k})$; curva da precipitação média mensal (1); período seco (não existente) $(\mathrm{m})$; período úmido $(\mathrm{n})$; meses com precipitação maior do que $100 \mathrm{~mm}$ (o) (Adaptado de Durigan et al. 1995).

Figure 1. Climate diagram of the Ecological Station and Assis State Forest, according to Walter \& Lieth (1967). Location (s); altitude (b); observation period (c); mean annual temperature (d); mean annual rainfall (e); mean minimum temperature of the coldest month (f); lowest temperature observed (g); mean maximum temperature of the warmest month $(\mathrm{h})$; maximum temperature observed (i); mean daily temperature amplitude (j); curve of the monthly average temperature $(\mathrm{k})$; curve of the monthly average precipitation (1); dry period (non existent) (m); wet period (n); months with precipitation above $100 \mathrm{~mm}$ (o) (Adapted from Durigan et al. 1995). o ângulo médio e o comprimento do vetor $r$ para cada fenofase para os quatro anos de estudo, segundo Zar (1999). O comprimento do vetor $r$ representa uma medida da concentração de determinada fenofase em torno do ângulo médio, com valores variando de 0 a 1 , onde o valor 0 representa total uniformidade dos dados e o valor 1 reflete total agregação dos dados em torno do ângulo médio. O teste de Rayleigh $(Z)$ foi utilizado a fim de verificar a sazonalidade das fenofases (Zar 1999). Realizamos as análises por meio do software Oriana 4.1.

\section{Resultados}

Apresentamos na tabela 1 os meses de ocorrência de cada fenofase (floração, frutificação, brotação e caducifolia) para cada espécie, bem como suas respectivas frequências mensais (número de anos durante os quais registramos a fenofase naquele mês), ao longo dos quatro anos de registros.
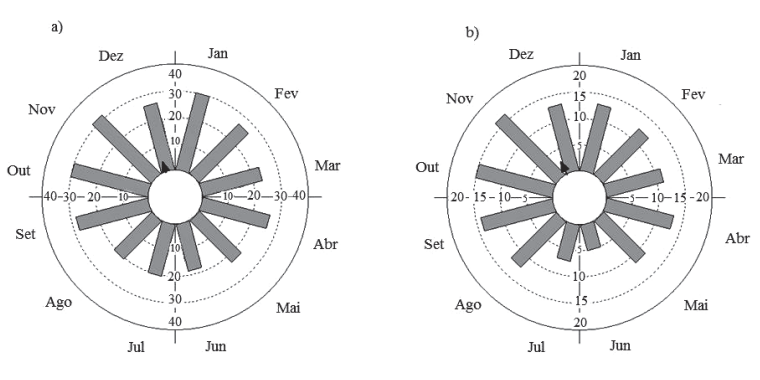

d)
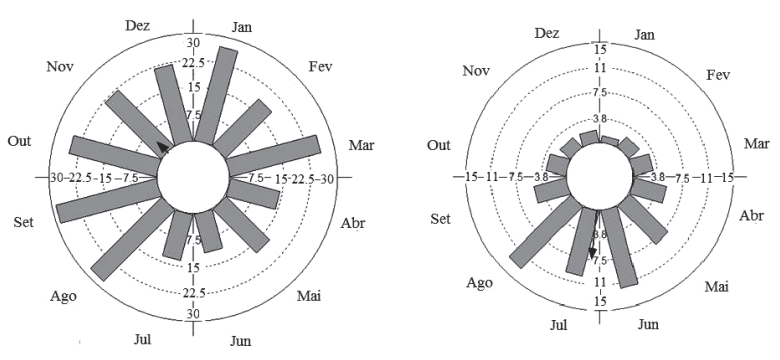

Figura 2. Histogramas circulares da frequência mensal (média de quatro anos de observações), expressa em porcentagem de espécies em cada fenofase no Arboreto do Cerrado da Floresta Estadual de Assis, SP, Brasil. a. floração; b. frutificação; c. brotação; d. queda de folhas. A seta de coloração preta representa o comprimento do vetor $r$ apontando para o ângulo médio.

Figure 2. Circular histograms of the monthly frequencies (average of four years of observations), expressed in percentage of species at each phenophase in the Arboretum of Cerrado at Floresta Estadual de Assis, SP, Brazil. a. flowering; b.fruiting; c. leaf flushing; d. leaf fall. The vector line in the circle (black arrow) indicates the mean angle. 
Tabela 1. Fenograma de floração, maturação de frutos, queda de folhas e brotação de espécies de Cerrado em condições de cultivo na Floresta Estadual de Assis, SP, Brasil. Floração: $\quad$, Frutificação:, , Brotação: $\square$, Queda de Folhas: ,
Ausência de Folhas: $\square$; a: Anemocoria; au; Autocoria; z; Zoocoria. Os algarismos no interior das células correspondem ao número de anos no qual a fenofase foi observada naquele mês para aquela espécie.

Table 1. Phenogram of flowering, fruit ripening, leaf fall and sprouting of Cerrado species under cultivation at the State Forest Assis, SP. Flowering: , Fruiting: $\quad$, Sprouting: $\square$, Falling Leaves: $\square$, Absence of leaves: $\square$; a: Anemochory; au: Autochory; z: Zoochory. The digits within the cells represent the number of years in which the phenophase was observed in that month for that species.

Espécie
Anadenanthera peregrina var. falcata (Benth.)
Altschul

Aegiphila verticillata Vell.

Arbóreo

$\begin{array}{cc}\text { Dispersão } & \text { Hábito } \\ \text { au } & \text { Arbóreo }\end{array}$

Altschul

Alibertia edulis L. Rich

Arbustivo

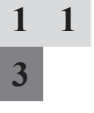

Anacardium humile A.St.-Hil.

Arbustivo

$\begin{array}{lll} & & 2 \\ 1 & 1 & 1\end{array}$

2

$\begin{array}{llllll}1 & 1 & 1 & 3 & 3 & 2\end{array}$

$\begin{array}{llllll}1 & 2 & 1 & 1 & 1 & 1\end{array}$

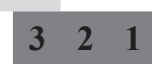

$\begin{array}{llll}1 & 3 & 3 & 2\end{array}$

3

1

$\begin{array}{llllll}1 & 1 & 2 & 2 & 1 & 2\end{array}$

$\begin{array}{lll}2 & 1 & 1\end{array}$

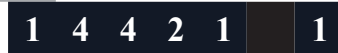

Anacardium occidentale L.

Arbustivo

$\begin{array}{lll}1 & 1 & 1\end{array}$

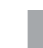

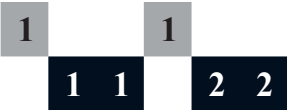

$\begin{array}{llll}1 & 1 & 1 & 1\end{array}$

a

Anemopaegma glaucum Mart. ex DC.

Arbustivo
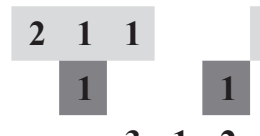

$\begin{array}{lllll}2 & 1 & 1 & 1 & 3\end{array}$

$\begin{array}{lll}3 & 1 & 2\end{array}$

$\begin{array}{llllll}3 & 4 & 5 & 3 & 1 & 1\end{array}$

$$
\frac{1}{1}
$$




\section{Tabela 1 (continuação)}

Espécie Dis

Arrabidaea sceptrum (Cham.)

Aspidosperma cuspa (Kunth) S.F. Blake ex Pittier

Aspidosperma macrocarpon Mart.

Aspidosperma tomentosum Mart.

Bauhinia rufa (Bong.) Steud.

Blepharocalyx salicifolius (Kunth) O.Berg

Bowdichia virgilioides Kunth

Brosimum gaudichaudii Trécul.

Byrsonima intermedia A.Juss.

Byrsonima laxiflora Griseb.
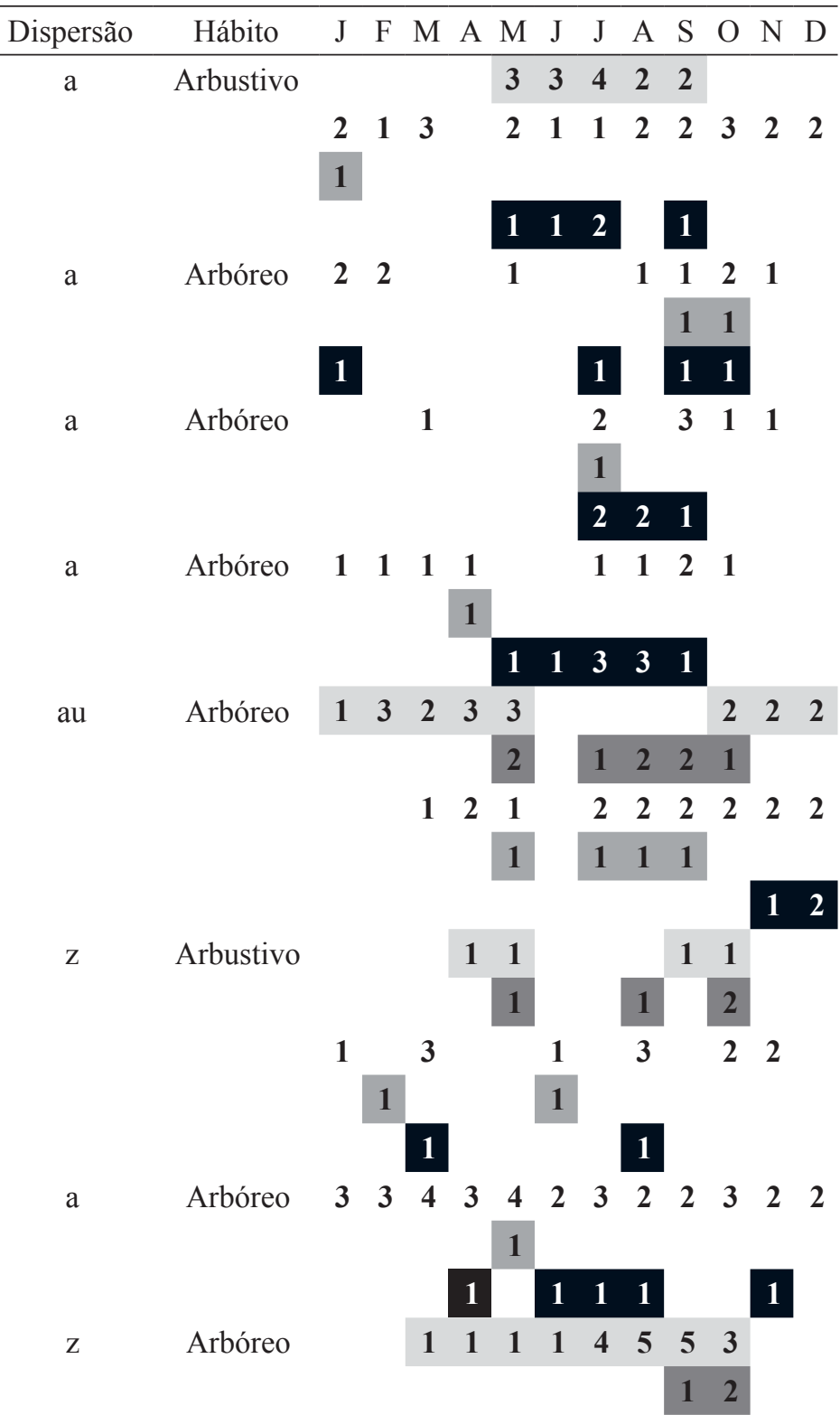

$\begin{array}{llll}3 & 3 & 2 & 1\end{array}$

$\begin{array}{llll}2 & 1 & 2 & 2\end{array}$

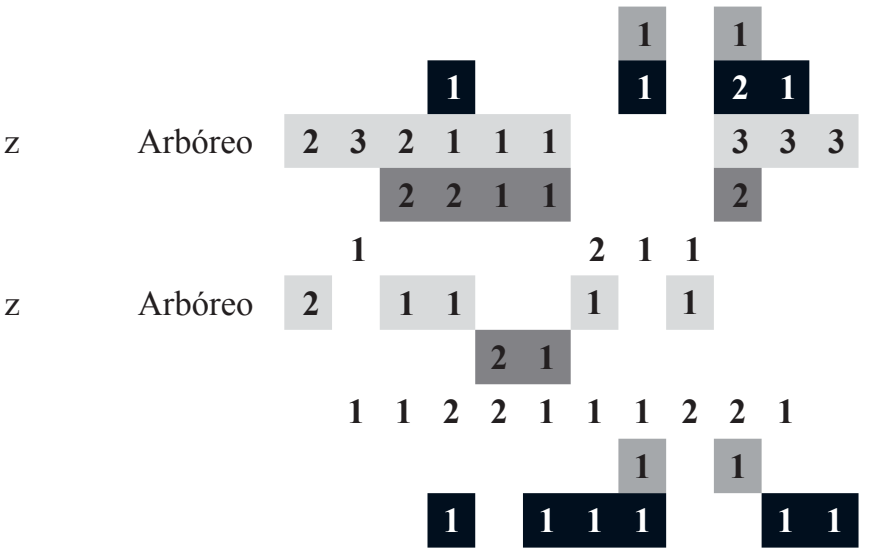

continua 
Tabela 1 (continuação)

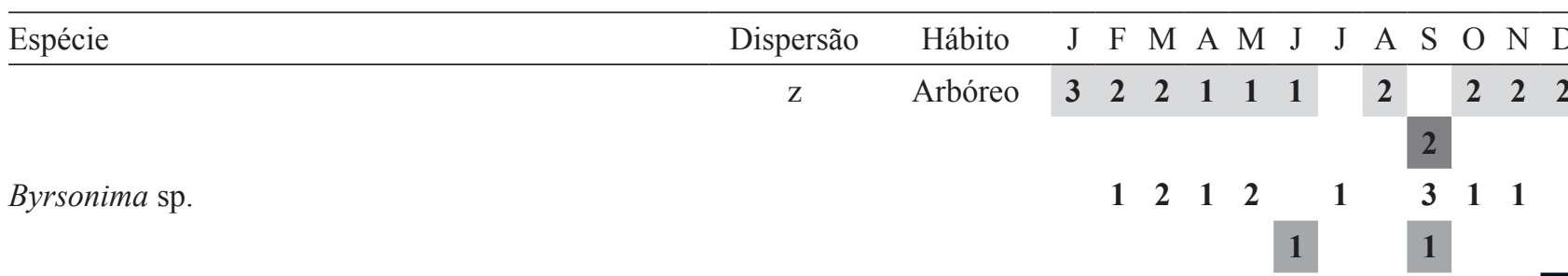

z Arbustivo

1

Campomanesia adamantium (Cambess.) O.Berg

Caryocar brasiliense Camb.

z

$\begin{array}{lllllllllll} & 3 & 1 & 2 & 1 & & 1 & 1 & 2 & 3\end{array}$
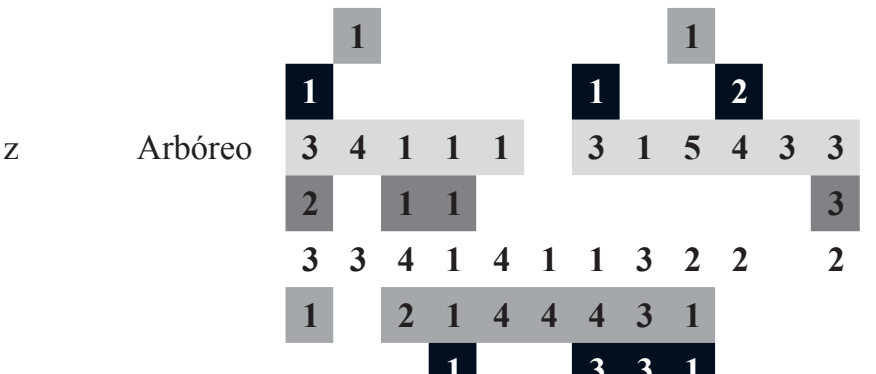

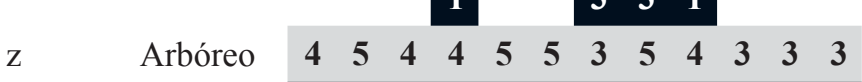

Cecropia pachystachya Trécul.

$\begin{array}{llllllllllll}3 & 4 & 4 & 4 & 5 & 5 & 3 & 5 & 4 & 4 & 4 & 4 \\ 3 & & 2 & 1 & 1 & 1 & 3 & 1 & 1 & & 2 & \end{array}$

au

au

Clitoria densiflora (Benth.) Benth.

Clitoria densiflora (Benth) Benth.

Cocoloba mollis Casar.

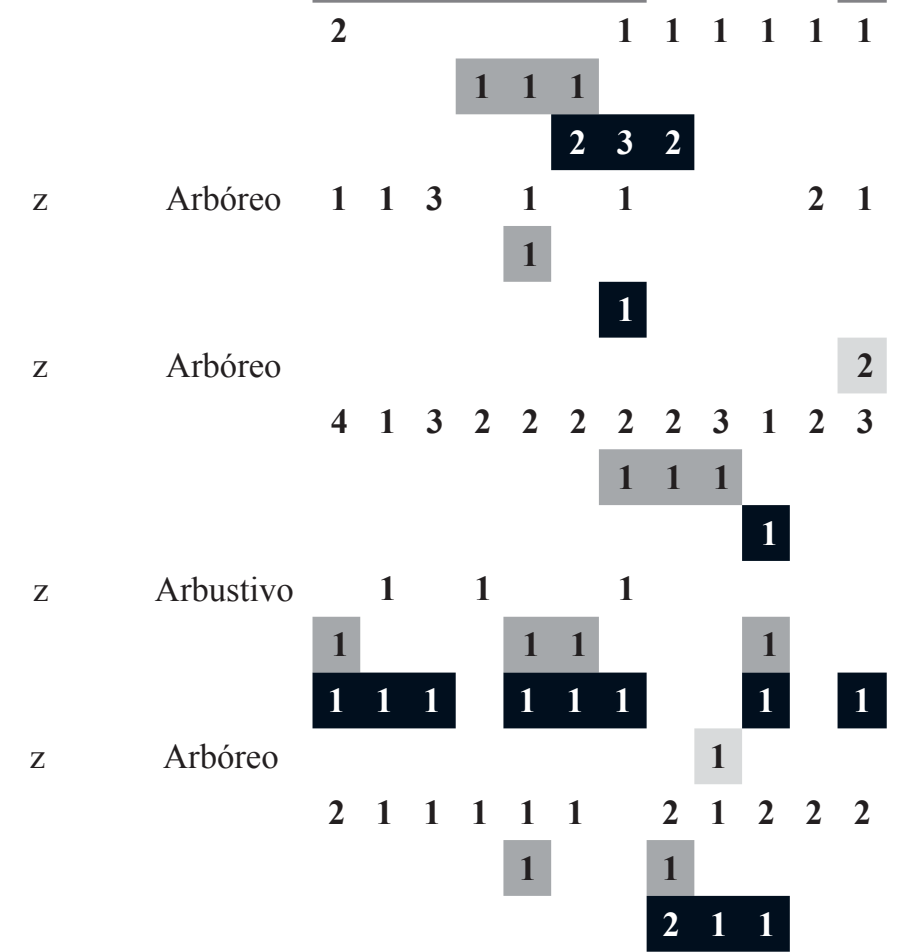

Coussarea hydrangeaefolia (Benth.) Müll.Arg.

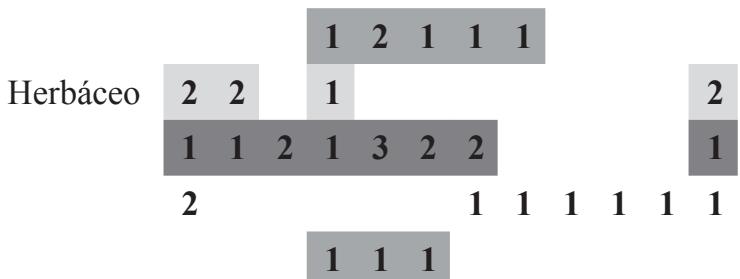

\section{$\begin{array}{lll}2 & 3 & 2\end{array}$}

1

Copaifera langsdorffii Desf.

Couepia grandiflora (Mart. \& Zucc.) Benth.

continua 
Tabela 1 (continuação)

\begin{tabular}{clllllllllllll} 
Dispersão & Hábito & J & F & M & A & M & J & J & A & S & O & N & D \\
\hline z & Arbóreo & & & & & $\mathbf{2}$ & $\mathbf{2}$ & $\mathbf{3}$ & $\mathbf{2}$ & $\mathbf{1}$ & & & \\
& & & & & & & & & $\mathbf{1}$ & $\mathbf{4}$ & $\mathbf{5}$ & $\mathbf{1}$
\end{tabular}

$\begin{array}{llll}1 & 4 & 5 & 1\end{array}$

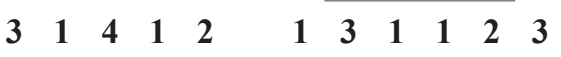

1

\section{$1 \quad 251$}

Espécie Dis

Cupania tenuivalvis Radlk.

Curatella americana $\mathrm{L}$.

Cybistax antisiphilitica (Mart.) Mart.

Dimorphandra mollis Benth.

Diospyros hispida A.DC.

Enterolobium gummiferum (Mart.) J.F.Macbr.

Eriotheca gracilipes (K.Schum) A. Robyns

Dipteryx alata Willd.
Duguetia furfuracea (A.St.-Hil.) Saff.

$\begin{array}{lllllllllllll}\text { Arbóreo } & 1 & 1 & 3 & 2 & 2 & 2 & 1 & 2 & 2 & 2 & 2 & 1\end{array}$

Z

1

$$
\begin{array}{llll}
1 & 1 & 2 & 1
\end{array}
$$

$\begin{array}{lll}1 & 1 & 1\end{array}$

Arbóreo

$$
\begin{array}{lllllllllllll}
2 & 2 & 3 & 2 & 2 & 1 & 1 & 3 & 3 & 3 & 2 & 3
\end{array}
$$

12

$\begin{array}{llllllll}2 & 2 & 2 & 4 & 4 & 2 & 3\end{array}$

au

Arbóreo

122

Arbóreo

\begin{tabular}{|l|l|} 
& 1 \\
2 & 3
\end{tabular}

$\begin{array}{lllll}2 & 2 & 1 & 1 & 2\end{array}$

Z

Arbóreo

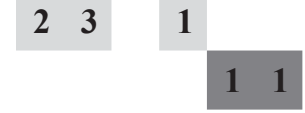

$\begin{array}{llllllllllll}1 & 2 & 2 & 2 & 4 & 2 & 3 & 4 & 3 & 3 & 2 & 2\end{array}$

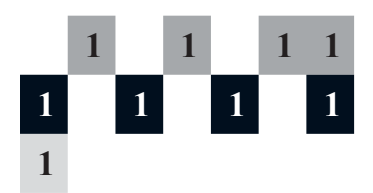

Arbóreo

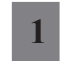

$\mathrm{z}$

Arbóreo

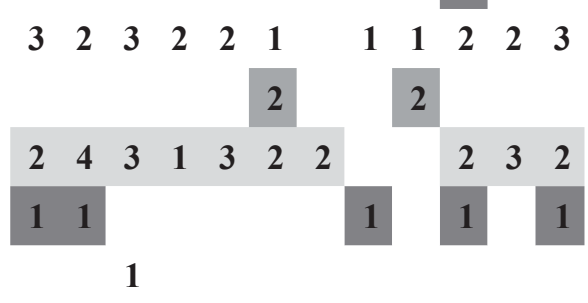

Arbóreo

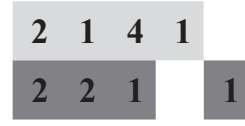

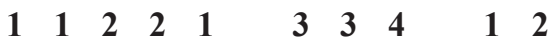

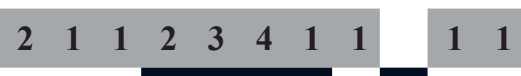 \begin{tabular}{llll|l}
1 & 2 & 4 & 4 & 1
\end{tabular}

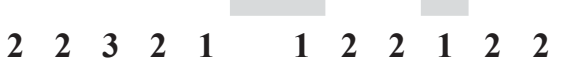

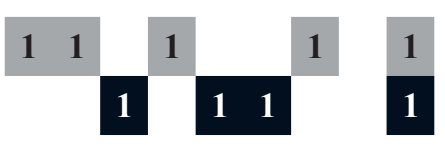
continua 


\section{Tabela 1 (continuação)}

\begin{tabular}{lr}
\hline Espécie & Dispersa \\
\hline Erythrina verna Vell. & \\
& $\mathrm{a}$ \\
& $\mathrm{z}$ \\
& \\
&
\end{tabular}

Erythroxylum deciduum A.St.-Hil.

Eugenia aurata O.Berg

Eugenia dysentherica DC.

Eugenia klotzschiana O.Berg

Eugenia pitanga (O.Berg) Nied.

Eugenia punicifolia (Kunth) DC.

Eugenia myrcianthes Nied.

Gochnatia polymorpha (Less.) Cabrera

$$
\text { Z }
$$

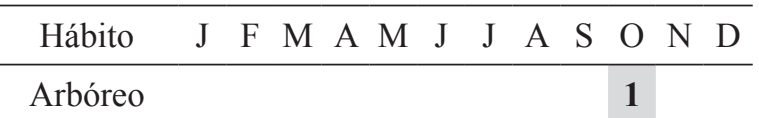
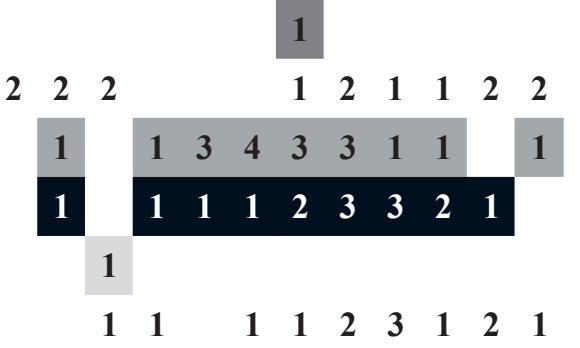

Arbustivo

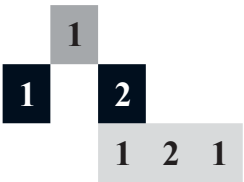

21

\section{1}

Arbustivo

1

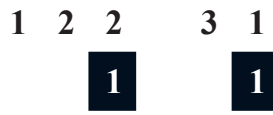

Arbustivo

$\begin{array}{llll}1 & 1 & 1 & 1\end{array}$

111

$$
11
$$

Arbustivo $\quad 2$

$\begin{array}{lll}1 & 2 & 1\end{array}$

$$
\text { Arbustivo }
$$

Arbustivo

$$
\begin{array}{lll}
2 & 3 & 3 \\
2 & 3 & 3
\end{array}
$$

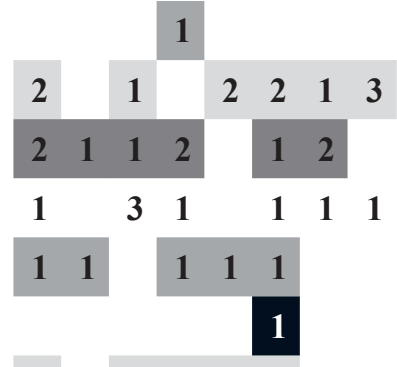

Arbóreo

1

$\begin{array}{llll}1 & 2 & 2 & 1\end{array}$

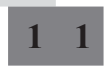

$\begin{array}{llllllllllll}2 & 3 & 2 & 2 & 3 & 3 & 2 & 3 & 3 & 2 & 3 & 3\end{array}$

$$
\begin{array}{lllllll}
1 & 1 & 1 & 2 & 3 & 1 & 1
\end{array}
$$

11

$\begin{array}{ll}3 & 1\end{array}$

Arbóreo

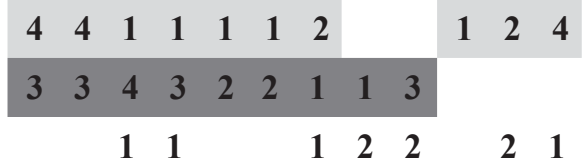

11

$\begin{array}{lllll}1 & 2 & 2 & 2 & 1\end{array}$

1

$\begin{array}{lllll}1 & 1 & 2 & 1\end{array}$ 
Tabela 1 (continuação)

Espécie
Gomphrena macrocephala A.St.-Hil.

Hymenaea courbaril $\mathrm{L}$.

Hymenaea stigonocarpa Mart. ex Hayne

Jacaranda caroba (Vell.) DC.

Jacaranda cuspidifolia Mart

Jacaranda decurrens Cham.

Jacaranda rufa Silva Manso

Inga laurina $(\mathrm{Sw}$.$) Willd$
Hancornia speciosa Gom.

$\begin{array}{cc}\text { Dispersão } & \text { Hábito } \\ \text { a } & \text { Herbáceo }\end{array}$

1

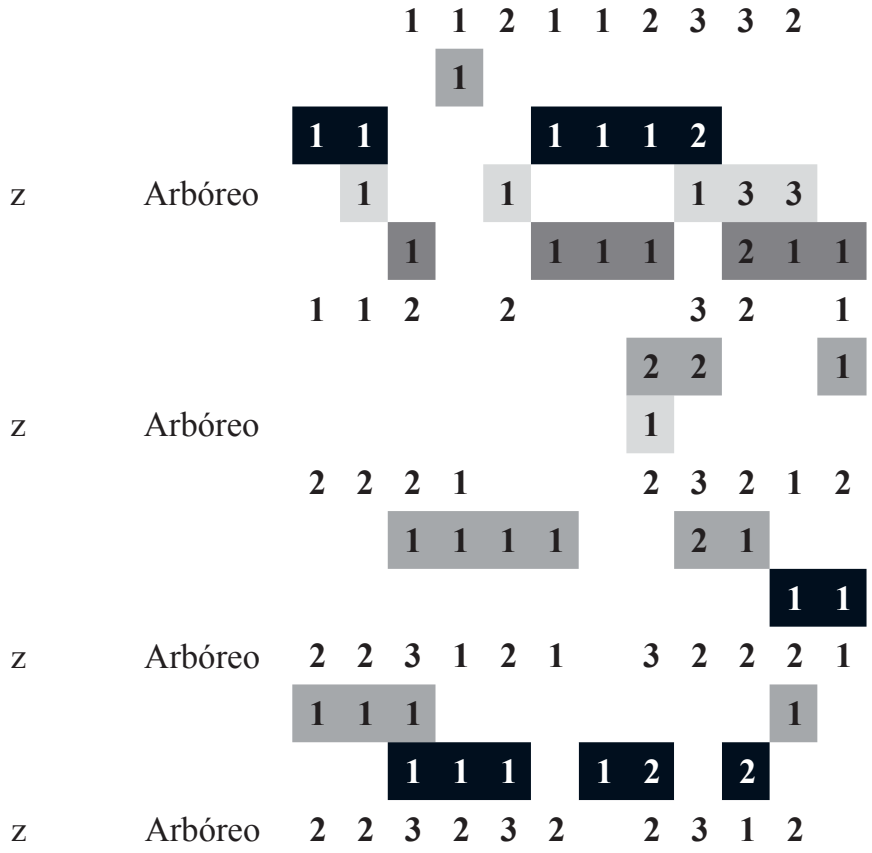

a

Arbustivo

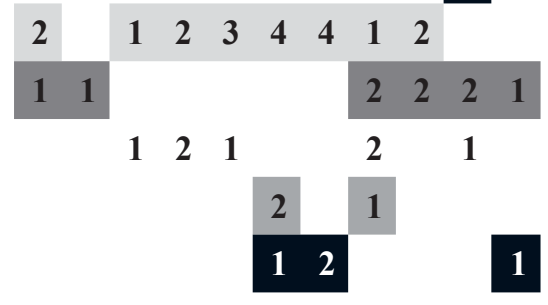

Arbóreo

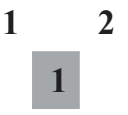

Herbáceo

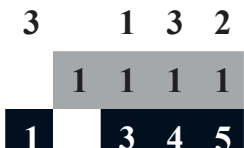

21

$\mathrm{a}$
21

1

1

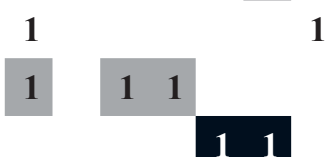

Arbustivo 21

$\begin{array}{lll}1 & 1 & 1\end{array}$

$\begin{array}{lll}1 & 1 & 2 \\ & 2 & 1\end{array}$

1 
Tabela 1 (continuação)

Espécie

Kielmeyera coriacea Mart. \& Zucc.

Kielmeyeria grandiflora (Wawra) Saddi

Kielmeyera latrophyton Saddi

Lafoensia pacari A. St.-Hill

Lafoensia vandelliana Cham. \& Schltdl.

Leptolobium elegans Vogel

Lippia lupulina Cham.

Lithraea molleoides (Vell.) Engler

Mabea fistulifera Mart.

\begin{tabular}{cccccccccccccc} 
Dispersão & Hábito & J & F & M & A & M & J & J & A & S & O & N & D \\
\hline a & Arbustivo & $\mathbf{2}$ & $\mathbf{1}$ & $\mathbf{1}$ & $\mathbf{1}$ & $\mathbf{1}$ & & & & & $\mathbf{3}$ & $\mathbf{3}$ & $\mathbf{3}$
\end{tabular}

$\begin{array}{llll}1 & 2 & 2 & 1\end{array}$

$\begin{array}{llllllllllll}2 & 1 & 2 & 1 & 2 & 1 & 1 & 4 & 3 & 2 & 2 & 4\end{array}$

$\begin{array}{llllll}1 & 1 & 2 & 4 & 5 & 2\end{array}$

$\begin{array}{lllllll}1 & 1 & 1 & 1 & 4 & 3 & 1\end{array}$

a Arbustivo

$\begin{array}{llllll}1 & 1 & 2 & 1 & 1 & 2\end{array}$

1

$\begin{array}{lll}3 & 2 & 2\end{array}$

a

$\begin{array}{lllllllllllll}\text { Arbustivo } & \mathbf{1} & \mathbf{3} & \mathbf{2} & \mathbf{1} & \mathbf{1} & \mathbf{1} & \mathbf{2} & \mathbf{4} & \mathbf{1} & \mathbf{2} & \mathbf{2} & \mathbf{1}\end{array}$

1

a

Arbóreo

$\begin{array}{lllll}4 & 4 & 5 & 3 & 2\end{array}$

11

$\begin{array}{lllllllllll}1 & 3 & 3 & 1 & 3 & 2 & 3 & 5 & 4 & 3 & 2\end{array}$

$\begin{array}{lllllll}1 & 2 & 1 & 3 & 3 & 2 & 1\end{array}$

$1 \quad 3 \quad 3 \quad 2$

a

Arbustivo

$\begin{array}{lllll}3 & 4 & 4 & 5 & 1\end{array}$

111

122

$\begin{array}{llllll}1 & 1 & 2 & 2 & 2 & 1\end{array}$

1

$$
\begin{array}{llll}
1 & 3 & 4 & 2 \\
1 & 1 & 1
\end{array}
$$

Arbóreo

22

$\begin{array}{lll}1 & 1 & 1\end{array}$

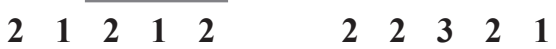
$\begin{array}{lllllll}1 & 3 & 3 & 4 & 4 & 4 & 1\end{array}$

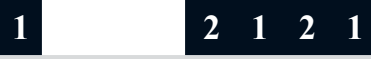

Arbustivo

$\begin{array}{llllllllllll}4 & 5 & 4 & 4 & 5 & 3 & 4 & 4 & 4 & 4 & 2 & 3\end{array}$

\section{1}

Arbóreo

22

Z$$
\text { Arbóreo }
$$$$
1
$$

Arbóreo $\begin{array}{llllllllllll}3 & 1 & 3 & 1 & 3 & 1 & & 1 & 1 & 1 & 2 & 1\end{array}$

au

$\begin{array}{llllll}2 & 1 & 3 & 1 & 4 & 3\end{array}$ $\begin{array}{lll}3 & 3 & 1\end{array}$ $11 \frac{1}{1} 1$

continua 
Tabela 1 (continuação)

Espécie

Machaerium acutifolium Vogel.

Machaerium brasiliense Vogel

Magonia pubescens A.St.-Hil.

Maprounea guianensis Aubl.

Matayba elaeagnoides Radlk.

Melothria campestris (Naudin) H. Schaef.\& S.S. Renner

Miconia albicans (Sw.) Triana

Myrcia guianensis (Aubl.) DC.

Myrcia splendens (Sw.) DC.

Nectandra cuspidata Ness

Nectandra grandiflora Nees a

a

$\begin{array}{llllllllllllll}\text { Arbóreo } & \mathbf{3} & \mathbf{1} & \mathbf{2} & & & \mathbf{2} & \mathbf{3} & \mathbf{2} & \mathbf{2} & \mathbf{1} & \mathbf{1} & \mathbf{2}\end{array}$

Arbóreo 2

Arbóreo

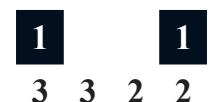

12 $\begin{array}{llllll}1 & 1 & 1 & 1 & 2 & 2\end{array}$

\begin{tabular}{lllll|l}
1 & 1 & 4 & 2 & & 1
\end{tabular}

a Arbóreo

1

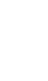

a

Z

Z

Z

(2)

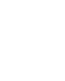

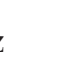

(n)


Tabela 1 (continuação)

Espécie

Ocotea vellozziana (Meissn.) Mez.

Ormosia arborea (Vell.) Harms

Ouratea nervosa (A.St.-Hil.) Engl.

Parkia platycephala Benth.

Physocalymma scaberrimum Pohl

Plathymenia reticulata Benth.

Platypodium elegans Vogel.

Plenckia populnea Reissek

Pouteria ramiflora (Mart.) Radlk.

Protium heptaphyllum (Aubl.) Marchand.

Prunus myrtifolia (L.) Urb.

\begin{tabular}{clrrrrrrrr} 
Dispersão & Hábito & J & F & M & A & M & J & J & A \\
\hline Z & Arbóreo & & & & $\mathbf{1}$ & & $\mathbf{1}$ & $\mathbf{1}$
\end{tabular}

$\begin{array}{llllllllllll}2 & 1 & 1 & 1 & 1 & 1 & & 2 & 1 & & 2 & 2\end{array}$

1

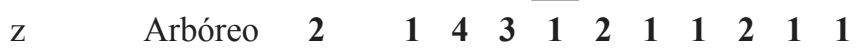

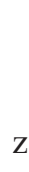

Z

$\mathrm{au}$

a Arbóreo
Arbustivo

$$
\begin{array}{ll} 
& 1 \\
2 & 1
\end{array}
$$$$
111
$$

Arbóreo $\begin{array}{llllll}2 & 1 & 1 & & 2 & 1 \\ 2 & 1 & 3 & 1 & 2 & 1\end{array}$

\section{1}

$\begin{array}{llllllllllll}2 & 3 & 4 & 2 & 2 & 1 & 1 & 3 & 1 & 2 & 2 & 2\end{array}$
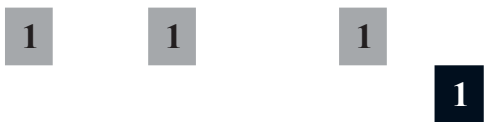

a

Arbóreo

111

$\begin{array}{llll}1 & 2 & 2 & 2\end{array}$

$\begin{array}{lllllll}2 & 2 & 3 & 3 & 4 & 4 & 2\end{array}$

$\begin{array}{lllll}2 & 2 & 2 & 1 & 1\end{array}$

a

Arbóreo

$\begin{array}{llllllll}1 & 1 & 2 & 1 & 2 & 1 & 1\end{array}$

$\begin{array}{llllll}1 & 2 & 1 & 1 & 2 & 1\end{array}$

$\begin{array}{lllll}1 & 1 & 1 & 3 & 1\end{array}$

a

Arbóreo

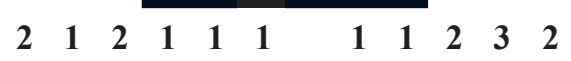

1

$\begin{array}{lll}2 & 1 & 2\end{array}$

Arbóreo

$\begin{array}{llllll}2 & 1 & 2 & 4 & 3 & 2\end{array}$

$\begin{array}{lllll}2 & 1 & 1 & 1 & 2\end{array}$

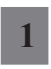

Arbóreo

11

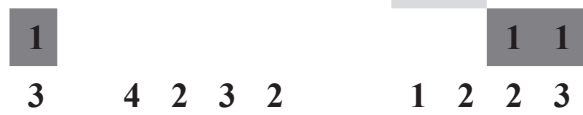

Arbóreo

$\begin{array}{llll}3 & 3 & 2 & 2\end{array}$

\section{1}

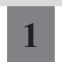

$\begin{array}{llllllllllll}2 & 2 & 3 & 2 & 2 & & 2 & 3 & 1 & 2 & 2 & 1\end{array}$

\begin{tabular}{lll|ll}
1 & 1 & 1 & 1 & 1
\end{tabular}

1

112 
Tabela 1 (continuação)

Espécie
Pseudobombax longiflorum (Mart. \& Zucc.)
A.Robyns

Pseudobombax tonentozum (Mart. \& Zucc.) A.Robyns

Psidium guineense SW.

Qualea cordata (Mart.) Spreng.

Qualea dichotoma (Mart.) Warm.

Qualea grandiflora Mart.

Qualea multiflora Mart.

Roupala montana Aubl.

Schefflera macrocarpa (Cham. \& Schltdl) Frodin

\begin{tabular}{cccccccccccccc} 
Dispersão & Hábito & J & F & M & A & M & J & J & A & S & O & N & D \\
\hline a & Arbóreo & $\mathbf{3}$ & $\mathbf{1}$ & $\mathbf{1}$ & $\mathbf{2}$ & & & $\mathbf{1}$ & $\mathbf{2}$ & $\mathbf{3}$ & $\mathbf{3}$ & $\mathbf{2}$
\end{tabular}

$\begin{array}{lll}4 & 1 & 1\end{array}$

$\begin{array}{llllllllll}1 & 1 & 2 & 3 & 3 & 5 & 4 & 2 & 1\end{array}$

Arbóreo

$\begin{array}{lll}2 & 3 & 1\end{array}$ $\begin{array}{lllll}2 & 1 & 3 & 2 & 2\end{array}$ \begin{tabular}{ll|lll|l}
1 & 1 & 3 & 1 & 1
\end{tabular}

$\begin{array}{llllll}1 & 2 & 3 & 3 & 4\end{array}$

$\begin{array}{lllllllllllll}\text { Arbustivo } & 2 & 1 & 1 & 1 & 2 & & 1 & 3 & 2 & 2 & 1\end{array}$ $\begin{array}{lllllllll}1 & 1 & & 2 & 1 & 1 & 1 & 1 & 1\end{array}$

$\begin{array}{llllllllll}2 & 2 & 3 & 2 & 3 & 1 & 2 & 4 & 2 & 2\end{array}$

a

Arbóreo

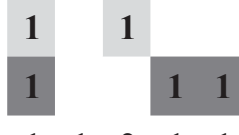

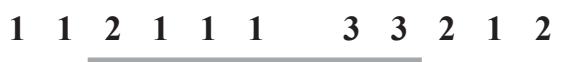

$\begin{array}{lllllll}1 & 2 & 5 & 5 & 4 & 2 & 1\end{array}$

$\begin{array}{lllll}1 & 1 & 5 & 4 & 2\end{array}$

a

Arbóreo

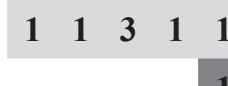

$1 \quad 11$

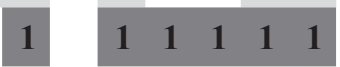

$\begin{array}{llll}2 & 1 & 2 & 1\end{array}$ $\begin{array}{llll}1 & 2 & 3 & 1\end{array}$ 1

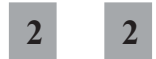

$\begin{array}{llll}1 & 3 & 2 & 2\end{array}$

a

a

Arbóreo

Arbóreo

$$
1
$$

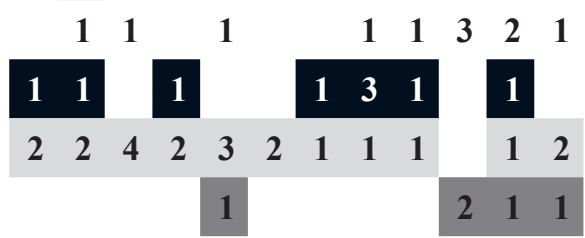

$\begin{array}{lll}1 & 3 & 1\end{array}$

$\begin{array}{lll}1 & 1 & 1\end{array}$

13

11

a

Arbóreo

224
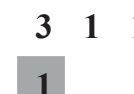

1

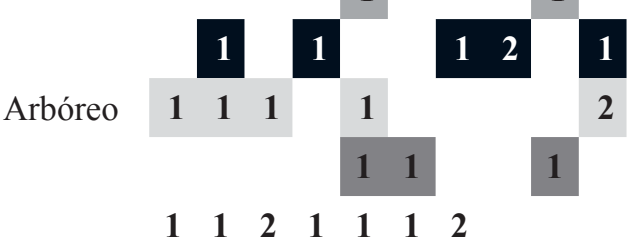

11 
Tabela 1 (continuação)

Espécie Dis

Senna macranthera (Collad) H.S.Irwin \& Barneby

\begin{tabular}{cl} 
Dispersão & Hábito \\
\hline au & Arbóreo
\end{tabular}

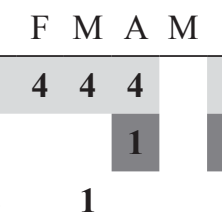

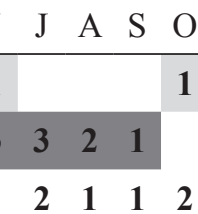

Senna velutina (Vogel) H.S. Irwin \& Barneby

Strychnos brasiliensis Mart.

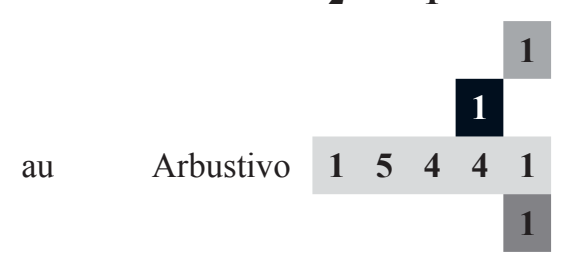

21

$\begin{array}{lll}1 & & 2 \\ 1 & 2 & 1\end{array}$

1

$\begin{array}{lll}4 & 4 & 4\end{array}$

$$
\text { Z }
$$

$\mathrm{au}$

Stryphnodendron adstringens (Mart.) Coville

Stryphnodendron rotundifolium Mart.

Styrax camporum Pohl.

Syagrus flexuosa (Mart.) Becc.

Tabebuia aurea (Silva Manso) Benth. \& Hook.f. ex S.Moore

$\begin{array}{llll}2 & 2 & 1 & 1\end{array}$ 1

Arbustivo$$
\begin{array}{llllllllllll}
1 & 1 & 2
\end{array}
$$

Arbóreo

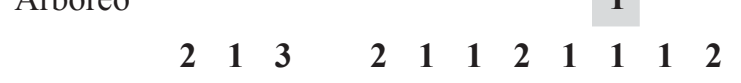

au

Arbóreo
112

\section{1}

$\begin{array}{llll}3 & 1 & 1 & 2\end{array}$

11

1

22

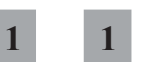

1

11 $\begin{array}{lllllll}1 & 1 & 2 & 2 & 2 & 2 & 2\end{array}$

$\begin{array}{llll}1 & 1 & 1 & 2\end{array}$

$\begin{array}{llll}2 & 1 & 1\end{array}$

1

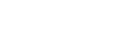
23

1

$\begin{array}{lllll}1 & 3 & 3 & 1 & 2\end{array}$

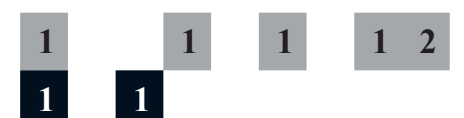

Arbóreo

$\begin{array}{llllllllllll}5 & 5 & 4 & 5 & 4 & 5 & 4 & 3 & 2 & 4 & 4 & 4\end{array}$

$\begin{array}{llllllllllll}2 & 1 & 1 & 1 & 2 & 2 & 2 & 2 & 1 & 2 & 1 & 2\end{array}$

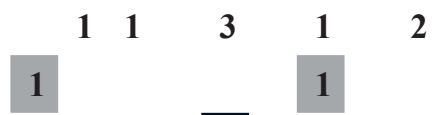

1

Arbóreo

$\begin{array}{llll}2 & 1 & 1 & 1\end{array}$

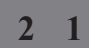

1

1

1

Arbóreo

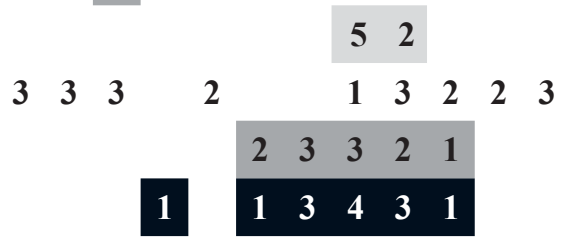


Tabela 1 (continuacão)

\begin{tabular}{|c|c|c|c|c|c|c|c|c|c|c|c|c|c|c|}
\hline Espécie & Dispersão & Hábito & $\mathrm{J}$ & $\mathrm{F}$ & M & A & M & $\mathrm{J}$ & $\mathrm{J}$ & A & $\mathrm{S}$ & $\mathrm{O}$ & & $\mathrm{D}$ \\
\hline \multirow{4}{*}{ Terminalia argentea Mart. } & $\mathrm{a}$ & Arbóreo & & & 1 & & & & & & 1 & 1 & & \\
\hline & & & 2 & 2 & 4 & 2 & 2 & 1 & 1 & 1 & 3 & 2 & 3 & 2 \\
\hline & & & & & & & 4 & 2 & 2 & 5 & 2 & & & \\
\hline & & & & & & & & & & 2 & 2 & 1 & & \\
\hline \multirow{4}{*}{ Terminalia glabrescens Mart. } & $\mathrm{a}$ & Arbóreo & & & & & & & & & 1 & 1 & 1 & \\
\hline & & & 2 & 2 & 4 & 3 & 3 & 1 & 2 & 5 & 2 & 3 & 2 & 2 \\
\hline & & & & & 1 & 2 & 1 & 1 & 5 & 1 & 1 & & & \\
\hline & & & & & & & & 1 & 1 & 3 & 2 & & 1 & 1 \\
\hline \multirow{3}{*}{ Vitex polygama Cham. } & $\mathrm{Z}$ & Arbóreo & & & & & & & & & 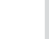 & 1 & 2 & \\
\hline & & & & & 1 & 1 & 3 & & 1 & 1 & 2 & 1 & 2 & 1 \\
\hline & & & 1 & 1 & 1 & & & & 2 & & & & & 1 \\
\hline \multirow{4}{*}{ Vochysia tucanorum Mart. } & $\mathrm{a}$ & Arbóreo & 4 & 4 & 4 & 4 & 3 & 2 & 1 & 3 & 2 & 2 & 4 & 4 \\
\hline & & & & & & & & & & 2 & 3 & 4 & 2 & \\
\hline & & & & & & 2 & 1 & & 1 & 1 & 1 & & 1 & \\
\hline & & & & & & 1 & 1 & & & 1 & & & & \\
\hline \multirow{4}{*}{ Xylopia aromatica (lam.) Mart. } & $\mathrm{z}$ & Arbóreo & 4 & 4 & 4 & 3 & 3 & 2 & 3 & 2 & 4 & 4 & 3 & 3 \\
\hline & & & & 1 & 3 & 2 & 2 & 1 & & 2 & 2 & 1 & 2 & 1 \\
\hline & & & & 1 & 2 & 2 & & 1 & 1 & 1 & 1 & & 1 & 1 \\
\hline & & & & & & & & 1 & & & 2 & & & 1 \\
\hline \multirow{4}{*}{ Zeyheria montana Mart. } & $\mathrm{a}$ & Arbustivo & 3 & 2 & 4 & 4 & 3 & 3 & 4 & 2 & 1 & & & 1 \\
\hline & & & 3 & 3 & 3 & & 1 & 1 & 1 & 2 & 3 & 3 & 2 & 2 \\
\hline & & & & & & & & & 2 & 2 & 1 & 1 & & \\
\hline & & & 1 & 1 & 1 & & & & 2 & 3 & 1 & 2 & 1 & 1 \\
\hline \multirow{3}{*}{ Zeyheria tuberculosa (Vell.) Bureau ex Verl. } & $\mathrm{a}$ & Arbóreo & 2 & 2 & 4 & 2 & 4 & 2 & 2 & 5 & 4 & 3 & 3 & 3 \\
\hline & & & & 1 & 1 & 1 & & & 1 & 1 & & 1 & & \\
\hline & & & & 1 & 1 & 1 & & & 2 & 2 & & 2 & & \\
\hline
\end{tabular}

Fenologia reprodutiva - Quando analisamos o conjunto total de espécies, observamos eventos de floração ao longo de todo o ano. O teste de Rayleigh foi significativo apenas para o $2^{\circ}$ e o $3^{\circ}$ ano de observações, apontando a fenofase concentrada principalmente entre os meses de dezembro e janeiro. No entanto, todos os vetores $r$ apresentaram valores baixos (tabela 2), indicando baixa sazonalidade, ou seja, uniformidade da distribuição das frequências de espécies apresentando flores ao longo do ano.

Os histogramas nos permitem identificar dois picos de floração, o primeiro na transição da estação seca para a chuvosa e o segundo no auge da estação chuvosa, padrão observado também para a brotação (figura 2a). Algumas espécies apresentaram indivíduos florescendo em todos os meses do ano. Com exceção de Lippia lupulina, que é anemocórica, as espécies com este comportamento fenológico têm seus diásporos dispersos pela fauna, como Cecropia pachystachya, Miconia albicans, Styrax camporum e Xylopia aromatica.

Para a fenofase de frutificação, a maioria das espécies apresentou síndrome de dispersão zoocórica (52\%), seguidas das espécies anemocóricas (38\%) e autocóricas (10\%). O teste de Rayleigh foi significativo apenas para os dois primeiros anos, sendo 
que os valores correspondentes aos vetores $r$ foram baixos para todos os anos. $\mathrm{O}$ teste apontou para valores médios de atividade concentrados principalmente entre novembro a janeiro (tabela 2). Esses resultados evidenciam baixa sazonalidade na produção de frutos (figura $2 b$ ), fenofase observada com menor frequência nos meses historicamente associados à deficiência hídrica (estação seca).

Observamos que a sazonalidade pouco marcada da produção de frutos, quando analisado o conjunto total de espécies, está relacionada com diferenças entre as síndromes de dispersão. Espécies com dispersão anemocórica apresentaram picos de dispersão a partir do início da estação seca e frequência máxima no final desta estação. Observamos padrão similar para as plantas com síndrome de dispersão autocórica. Já para as espécies com dispersão zoocórica, os picos de frutos maduros se concentraram nos períodos mais chuvosos do ano (figura 3). Quando somadas todas as espécies, o resultado é que existem espécies frutificando praticamente ao longo de todo o ano.

Algumas espécies apresentaram frutificação na maior parte do ano. Neste grupo predominam espécies zoocóricas (11\% do total de espécies deste grupo funcional), como Cecropia pachystachya, Eugenia punicifolia, Miconia albicans, Styrax camporum e Xylopia aromatica. Dentre as espécies anemocóricas, Gochnatia polymorpha e Lafoensia pacari apresentaram os mais longos períodos de dispersão, com duração superior a 10 meses em um ano.

Fenologia vegetativa - A frequência de espécies produzindo folhas novas apresentou pouca variação entre os meses do ano, assim como ocorreu com a fenofase de floração (figura 2c). O teste de Rayleigh não foi significativo para a brotação apenas no primeiro ano de estudo, com valores do vetor $r$ baixos para todos os anos. O teste apontou picos de atividade principalmente nos meses de novembro e dezembro. No entanto, ocorreram dois picos de brotação, sendo um na transição da estação seca para a estação chuvosa e o outro no auge da estação chuvosa (figura 2c).

As maiores frequências de queda de folhas ocorreram no período de abril a setembro, que compreende os meses mais secos e frios. Poucas espécies apresentaram considerável queda de folhas ou total perda de folhas, mesmo durante a estação mais seca do ano, sendo que a porcentagem máxima de espécies apresentando caducifolia em um mesmo mês foi de $15 \%$, no mês de agosto (figura 2d). Analisando os padrões de caducifolia para cada ano separadamente evidenciamos alta sazonalidade desta fenofase. $\mathrm{O}$ teste de Rayleigh foi significativo para todos os anos estudados, com altos valores para o vetor $r$, apontando para ocorrência de pico de queda de folhas entre os meses de junho e julho (tabela 2).

Dentre todas as espécies cultivadas no arboreto, $59 \%$ comportaram-se como perenifólias, $20 \%$ brevidecíduas e $21 \%$ decíduas. Entre as espécies decíduas e brevidecíduas predomina dispersão de diásporos por anemocoria (66\%).

\section{Discussão}

Os ritmos fenológicos observados para as espécies estudadas, individualmente, apresentaram pequenas variações entre os quatro anos de observação para os períodos de florescimento, frutificação, brotação ou queda de folhas. Porém, é possível estabelecer os períodos mais prováveis para o florescimento ou a frutificação de cada espécie na região de estudo. Aparentemente, as fenofases respondem às condições climáticas locais, que representam o extremo sul da ocorrência do Cerrado no Brasil,

Tabela 2. Estatística descritiva da análise circular para os quatros anos de estudo (fevereiro de 2009 - março de 2013) das fenofases de espécies de Cerrado em condições de cultivo na Floresta Estadual de Assis, SP, Brasil. Teste de Rayleigh com alfa estabelecido em 0,05 .

Table 2. Descriptive statistics of the circular analysis for the four years of phenophase study (February 2009 - March 2013) of Cerrado species under cultivation in Assis State Forest, São Paulo State, Brazil. Rayleigh test with alpha established at 0.05.

\begin{tabular}{lcccccccccccc}
\hline \multirow{2}{*}{ Ano } & \multicolumn{3}{c}{ Angulo médio } & \multicolumn{4}{c}{ Vetor $r$} & \multicolumn{4}{c}{ Teste de Rayleigh $(p)$} \\
\cline { 2 - 12 } & $1^{\circ}$ & $2^{\circ}$ & $3^{\circ}$ & $4^{\circ}$ & $1^{\circ}$ & $2^{\circ}$ & $3^{\circ}$ & $4^{\circ}$ & $1^{\circ}$ & $2^{\circ}$ & $3^{\circ}$ & $4^{\circ}$ \\
\hline Floração & $61^{\circ}$ & $5^{\circ}$ & $359^{\circ}$ & $334^{\circ}$ & 0.09 & 0.18 & 0.22 & 0.10 & 0.42 & $<0.01^{*}<0.01^{*}$ & 0.07 \\
Frutificação & $353^{\circ}$ & $6^{\circ}$ & $318^{\circ}$ & $299^{\circ}$ & 0.30 & 0.21 & 0.08 & 0.08 & $0.01^{*}$ & $0.02^{*}$ & 0.56 & 0.42 \\
Brotação & $331^{\circ}$ & $276^{\circ}$ & $22^{\circ}$ & $310^{\circ}$ & 0.12 & 0.11 & 0.21 & 0.19 & 0.08 & $0.02^{*}<0.01^{*}<0.01^{*}$ \\
Caducifolia & $191^{\circ}$ & $160^{\circ}$ & $162^{\circ}$ & $220^{\circ}$ & 0.59 & 0.44 & 0.48 & 0.59 & $<0.01^{*}<0.01^{*}<0.01^{*}<0.01^{*}$ \\
\hline
\end{tabular}


com temperaturas mais amenas e estação seca de menor duração em relação às demais regiões. Não se pode, no entanto, extrapolar sem restrições a periodicidade das fenofases observada para cada uma das espécies estudadas para toda a extensa região de domínio do Cerrado, que apresenta amplas variações de temperatura, luminosidade, duração da seca e precipitação pluviométrica, entre outros fatores que influenciam as fenofases. No entanto, os ritmos fenológicos observados neste estudo para o conjunto das espécies de Cerrado cultivadas no arboreto assemelharam-se aos padrões mencionados na literatura para comunidades em savanas sazonais naturais (Sarmiento \& Monasterio 1983, Miranda 1995, Oliveira 2008).

Os dois picos de floração, que coincidiram com os picos de brotação, pelo menos para os anos nos quais os testes foram significativos, revelaram o mesmo padrão encontrado na literatura para a floração de comunidades em vegetações savânicas naturais, com elevada proporção de espécies que florescem no final da estação seca (Batalha et al. 1977, Tannus et al. 2006, Pirani et al. 2009, Silva et al. 2011, Borges $\&$ Prado 2014). De acordo com Oliveira (2008), a previsibilidade dos fatores climáticos no Cerrado pode explicar, em parte, os picos de floração precoce associados aos picos de brotação no final da estação seca, antes mesmo das primeiras chuvas.
Os dois picos de frutificação foram elucidados quando analisamos separadamente grupos de espécies de acordo com sua síndrome de dispersão. A baixa sazonalidade da frutificação para o conjunto total de espécies esconde forte sazonalidade dentro de grupos funcionais por síndrome de dispersão, com zoocóricas frutificando na estação chuvosa e as demais espécies no final da estação seca. O pico de frutos maduros das espécies anemocóricas e autocóricas no final da estação seca apresenta-se como importante estratégia de dispersão, uma vez que as condições nesta estação (mais ventos e menor umidade relativa) são mais propícias para a abertura dos frutos secos e para o transporte das sementes pelo vento, permitindo que os propágulos alcancem maiores distâncias (Batalha \& Martins 2004, Lenza \& Klink 2006, Pirani et al. 2009). A maior proporção de espécies caducifólias apresentando dispersão anemocórica também é reflexo dessa estratégia, sendo a abscisão foliar um meio para diminuir as barreiras que dificultam a dispersão. As espécies com síndrome de dispersão zoocórica apresentaram seus picos de dispersão durante a estação chuvosa, quando a maior umidade permite que os frutos permaneçam atrativos para seus dispersores por período de tempo mais longo. Esses padrões são mencionados em ampla gama de estudos, em diversas áreas naturais de Cerrado sob climas sazonais (Mantovani \& Martins 1988, Miranda 1995, Batalha

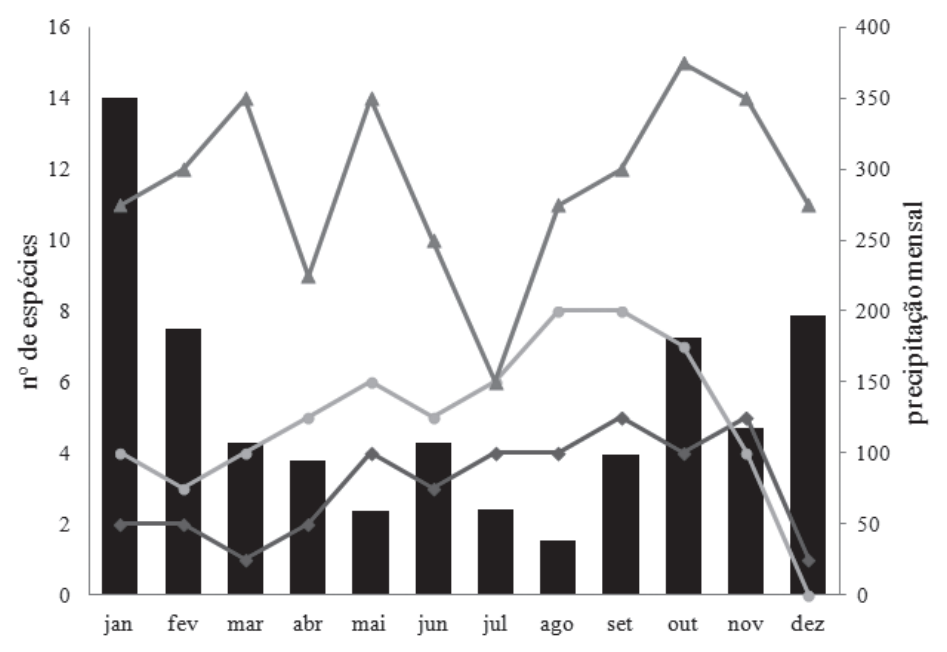

Figura 3. Picos de frutificação segundo a síndrome de dispersão ao longo do ano para espécies de Cerrado em condições de cultivo na Floresta Estadual de Assis, SP. As barras de precipitação representam a média mensal dos quatro anos de estudo (fonte para os dados de precipitação: Centro Integrado de Informações Agrometeorológicas - CIIAGRO, Instituto Agronômico de Campinas) - Precipitação, $\rightarrow$ Autocoria, $\rightarrow$ Anemocoria, $\rightarrow$ Zoocoria.

Figure 3. Peaks of fructification according to dispersal syndrome throughout the year of Cerrado species under cultivation at Assis State Forest, SP. The bars represent the average monthly rainfall of four years of study (source for rainfall data: Centro Integrado de Informações Agrometeorológicas - CIIAGRO, Instituto Agronômico de Campinas). - Precipitation, $\rightarrow$ Autochory, $\rightarrow$ Anemochory, - Zoochory. 
et al. 1997, Batalha \& Mantovani 2000, Vasconcelos et al. 2010).

A baixa proporção de espécies decíduas que observamos neste estudo demonstra que a vegetação do Cerrado é, como um todo, perenifólia, pois, para que a vegetação seja considerada semidecídua é preciso que pelo menos $20 \%$ dos indivíduos arbóreos do estrato dominante percam simultaneamente as folhas na estação desfavorável (IBGE 2012). A alta proporção de espécies perenifólias tem sido evidenciada em outras áreas de vegetação savânica na América do Sul (Monasterio \& Sarmiento 1976, Eamus 1999). A retenção das folhas é uma estratégia evolutiva de plantas que ocorrem em ambientes onde os nutrientes são escassos, já que o custo de produzir novas folhas seria elevado (Givnish 2002). A produção de folhas por espécies decíduas envolve maior mobilização de nutrientes do que se observa em espécies sempre-verdes (Eamus 1999, Araújo \& Haridasan 2007).

A frequência ligeiramente maior de espécies com queda de folhas nos meses mais secos do ano, tendo início em abril e cessando em setembro, representa estratégia para enfrentar o déficit hídrico, aumentando a eficiência no uso da água (Franco et al. 2005). Porém, estudos indicam que a sazonalidade climática não é estritamente o fator limitante para o comportamento fenológico de espécies lenhosas do Cerrado, evidenciando certa independência no que diz respeito aos ciclos anuais de precipitação, podendo algumas espécies brotar e florescer mesmo durante a estação seca (Sarmiento \& Monasterio 1983), sugerindo que outros fatores ambientais podem estar atuando na indução das fenofases. De fato, neste estudo observamos um pico de brotação subsequente ao pico de caducifolia, mas anterior ao início da estação chuvosa.

As informações aqui apresentadas, baseadas em observações de extenso número de espécies por um longo período, podem contribuir para a compreensão dos processos envolvidos na estruturação das comunidades em restauração e mesmo no funcionamento dos ecossistemas naturais do Cerrado. Demonstramos que, mesmo em condições de cultivo, os ritmos fenológicos dessa comunidade construída por intervenção humana assemelham-se aos padrões esperados para comunidades savânicas em ambientes naturais e de clima sazonal. Trata-se de um resultado favorável para a restauração do Cerrado, pois comprova que é possível restabelecer processos essenciais para o funcionamento dos ecossistemas savânicos, desde que sejam realizadas ações adequadas de manejo, como a reintrodução de um conjunto de espécies que represente as proporções entre grupos funcionais que ocorrem na natureza.

\section{Agradecimentos}

Aos funcionários da Floresta Estadual de Assis, pela colaboração durante a instalação e manutenção do arboreto; a Dora Souza Dias, pelo aprimoramento das figuras; a todos os colegas que contribuíram durante as atividades de campo deste estudo. Às editoras Maria Margarida R. Fiuza de Melo e Natália M. Ivanauskas e aos revisores anônimos, pela relevante contribuição para o aprimoramento deste artigo. Ao Conselho Nacional do Desenvolvimento Científico e Tecnológico - CNPq, pela bolsa de Iniciação Científica a Natashi A. Lima Pilon (Processo 112235/2011-5) e de Produtividade em Pesquisa a Giselda Durigan (Processo 303402/2012-1).

\section{Literatura citada}

Araújo, J.F. \& Haridasan, M. 2007. Relação entre deciduidade e concentrações foliares de nutrientes em espécies lenhosas do cerrado. Revista Brasileira de Botânica 30: 533-542.

Batalha, M.A., Aragaki, S. \& Mantovani, W. 1997. Variações fenológicas das espécies do cerrado em Emas (Pirassununga, SP). Acta Botanica Brasilica 11: 61-78.

Batalha, M.A. \& Mantovani, W. 2000. Reproductive phenological patterns of Cerrado plant species at the Péde-Gigante Reserve (Santa Rita do Passa a Quatro, SP, Brazil): comparison between the herbaceous and woody floras. Revista Brasileira de Biologia 60: 129-145.

Batalha, M.A. \& Martins, F.R. 2004. Reproductive phenology of the cerrado plant community in Emas National Park (central Brazil). Australian Journal of Botany 52: 149-16.

Borges, M.P. \& Prado, C.H.B.A. 2014. Relationships between leaf deciduousness and flowering traits of woody species in the Brazilian neotropical savanna. Flora-Morphology, Distribution, Functional Ecology of Plants 209: 73-80.

Chuine, I. \& Beaubien, E.G. 2001 Phenology is a major determinant of tree species range. Ecology Letters 4: 500-510.

Durigan, G. \& Leitao Filho, H.F. 1995. Florística e fitossociologia de matas ciliares do oeste paulista. Revista do Instituto Florestal 7: 197-239.

Eiten, G. 1972. The cerrado vegetation of Brazil. The Botanical Review 38: 201-341. 
Franco, A.C., Bustamante, M., Caldas, L.S., Goldstein, G., Meinzer, F.C., Kozovits, A.R., Rundel, P. \& Coradin, V.R.T. 2005. Leaf functional traits of Neotropical savanna trees in relation to seasonal water deficit. Trees 19: 326-335.

Gênova, K.B., Honda, E.A. \& Durigan, G. 2007. Processos hidrológicos em diferentes modelos de plantio de restauração de mata ciliar em região de cerrado. Revista do Instituto Florestal 19: 189-200.

Givnish, T.J. 2002. Adaptive significance of evergreen vs. deciduous leaves: Solving the triple paradox. Silva Fennica 36: 703-743.

Hoffman,W.A., Adasme, R., Haridasan, M., Carvalho, M.T., Geiger, E.L., Pereira, M.A.B., Gotsch, S.G. \& Franco, A. 2009. Tree topkill, not mortality, governs the dynamics of savana-forest boundaries under frequente fire in central Brazil. Ecology 90: 1326-1337.

Howe, H.F. 1994. Response of early-and late-flowering plants to fire season in experimental prairies. Ecological Applications 3: 121-133.

Instituto Brasileiro de Geografia e Estatística. 2012. Manual técnico da vegetação brasileira: sistema fitogeográfico, inventário das formações florestais e campestres, técnicas e manejo de coleções botânicas, procedimentos para mapeamentos. 2 ed. IBGE, Coordenação de Recursos Naturais e Estudos Ambientais, Rio de Janeiro.

Kucharik, C.J., Fayram, N.J. \& Cahill, K.N. 2006. A paired study of prairie carbon stocks, fluxes, and phenology: comparing the world's oldest prairie restoration with an adjacent remnant. Global change biology 12: 122-139.

Lenza, E. \& Klink, C.A. 2006. Comportamento fenológico de espécies lenhosas em um cerrado sentido restrito de Brasília, D.F. Revista Brasileira de Botânica 29: 627-638.

Mantovani, W. \& Martins, F.R. 1988. Variações fenológicas das espécies de cerrado da Reserva Biológica de Mogi Guaçu, Estado de São Paulo. Revista Brasileira de Botânica 11: 101-112.

Max, J.C.M., Melo, A.C.G., Honda, E.A., Durigan, G., Malicia, L.C., Souza, M.B.M., Cardoso, M.M., Vilas Boas, O., Ramos, V. \& Contieri, W.A. 2007. Plano de Manejo da Floresta Estadual de Assis. IF Série Registros 30: $1-80$

Miranda, I.S. 1995. Fenologia do estrato arbóreo de uma comunidade de cerrado em Alter-do-Chão. Revista Brasileira de Botânica 18: 235-240.
Monasterio, M. \& Sarmiento, G. 1976. Phenological strategies of plant species in the tropical savanna and the semi-deciduous forest of the Venezuelan Llanos. Journal of Biogeography 3: 325-355.

Morellato, L.P.C., Alberti, L.F., Hudson, I.L. 2010 Applications of circular statistics in plant phenology: a case studies approach. In: I.L. Hudson \& M. Keatley (orgs.). Phenological research: methods for environmental and climate change analysis. Springer, New York, pp. 339-359.

Munhoz, C.B.R. \& Jeanine, M.F. 2007. Reproductive phenology of an herbaceous-subshrub layer of a Savannah (Campo Sujo) in the Cerrado Biosphere Reserve I, Brazil. Brazilian Journal of Biology 67: 299-307.

Oliveira, P.E.A.M. 2008. Fenologia e biologia reprodutiva das espécies do Cerrado. In: Ecologia e flora. Embrapa, Brasília, pp. 275-286.

Pirani, J.R., Sanchez, M. \& Pedroni, F. 2009. Fenologia de uma comunidade arbórea em cerrado sentido restrito, Barra do Garças, MT, Brasil. Acta Botanica Brasilica 23: 1096-1109.

Sarmiento, G. \& Monasterio, M. 1983. Life forms and phenology. Ecosystems of the World 13: 79-108.

Selbo, S.M. \& Snow, A.A. 2005. Flowering phenology and genetic similarity among local and recently introduced populations of Andropogon gerardii in Ohio. Restoration Ecology 13: 441-447.

Silva, I.A., da Silva, D.M., Carvalho, G.H. \& Batalha, M.A. 2011. Reproductive phenology of Brazilian savannas and riparian forests: environmental and phylogenetic issues. Annals of Forest Science 68: 1207-1215.

Tannus, J.L.S., Assis, M.A. \& Morellato, L.P.C. 2006. Fenologia reprodutiva em campo sujo e campo úmido numa área de Cerrado no sudeste do Brasil, Itirapina SP. Biota Neotropica 6: 1-27.

Van Der Pijl, L. 1982. Principles of dispersal in higher plants. Springer-Verlag, New York.

Vasconcelos, S.F., de Araújo, F.S. \& Lopes, A.V. 2010. Phenology and dispersal modes of wood species in the Carrasco, a tropical deciduous shrubland in the Brazilian semiarid. Biodiversity and Conservation 19: 2263-2289.

Veldman, J.W., Mattingly, W.B. \& Brudvig, L. 2013. Understory plant communities and the functional distinction between savana trees, forest trees, and pines. Ecology 94: 424-434.

Walter, H. \& Lieth, H. 1960. Klimadiagramm-Weltatlas. Gustav Fischer Verlag, Jena.

Zar, J.H. 1999. Biostatistical analysis. Prentice Hall, Upper Saddle River. 